\title{
First-generation paclitaxel- vs. second-generation zotarolimus-eluting stents in small coronary arteries: the BASKET-SMALL Pilot Study
}

\author{
Raban Jeger, Matthias Pfisterer, Otmar Pfister, Peter Rickenbacher, Michael Handke, Nicole Gilgen, \\ Michael Coslovsky, Christoph Kaiser
}

Department of Cardiology and Clinical Trial Unit, University Hospital Basel, Basel, Switzerland

Adv Interv Cardiol 2016; 12, 4 (46): 314-320 DOI: 10.5114 /aic.2016.63630

\begin{abstract}
A bstract
Introduction: Event rates after percutaneous coronary interventions $(\mathrm{PCl})$ are higher in small than large coronary vessels but may vary between different drug-eluting stent (DES) types.

Aim: To assess the efficacy of two different DES in small vessel disease.

Material and methods: Patients with small vessel PCI were randomised $1: 1$ to a first-generation paclitaxel- vs. a second-generation zotarolimus-eluting stent. The primary endpoint was a composite of cardiac death, non-fatal myocardial infarction, and target vessel revascularisation after 2 years.

Results: Overall, 191 patients were enrolled: 100 with a paclitaxel- and 91 with a zotarolimus-eluting stent. Baseline characteristics were similar in both groups. After 2 years, rates of the primary endpoint were numerically higher for zotarolimus- than paclitaxel-eluting stents (9.9\% vs. $5.0 \%$, hazard ratio $2.09,95 \%$ confidence interval (Cl) $0.7-6.2, p=0.19$ ), which was mainly driven by higher rates of target vessel revascularisation ( $6.6 \%$ vs. $2.0 \%$, hazard ratio $3.39,95 \% \mathrm{Cl}: 0.68-16.78, p=0.14)$. Based on this, a total of 1,019 patients would be necessary to demonstrate at least non-inferiority between the DES used.

Conclusions: In this pilot study, paclitaxel-eluting stents had a favourable efficacy profile in small vessel disease, although the numbers were too small to draw final conclusions. Based on the prohibitively high sample size for a randomized controlled trial between DES, other treatment options should be considered.
\end{abstract}

Key words: small vessel disease, drug-eluting stent, paclitaxel, zotarolimus.

\section{Introduction}

Interventional treatment of small vessel disease remains challenging, mainly due to increased rates of ischaemic endpoints after percutaneous coronary intervention $(\mathrm{PCl})$. Most ischaemic endpoints are caused by in-stent restenoses, which generally are more frequent in small than in large coronary vessels because the absolute lumen loss after stent implantation comprises a larger proportional percentage of the total lumen diameter. Previous studies in small vessel disease have shown that drug-eluting stents (DES) are superior to bare metal stents (BMS) regarding both angiographic results and clinical events [1-3], a finding that was corroborated in a recent meta-analysis [4]. While rates for recurrent ischaemic events after implantation of DES are between $5 \%$ and $25 \%$ with somewhat better results for "limus"- than paclitaxel-eluting stents in a general population [5-8], there was equipoise between "limus"- and paclitaxel-eluting stents in the subgroup of patients with diabetes mellitus, who normally suffer from small vessel disease [9-11]. In contrast, a recent randomised controlled trial in small vessel disease showed the superiority of everolimus- over paclitaxel-eluting stents in a selected high-risk diabetic population from India [12]. Finally, although improvements in stent technology were thought to further decrease both late lumen loss and ischaemic event rates in small vessel disease, newer-generation stents seem to show a similar effectiveness as first-generation products [13-15]. In this context, randomised data comparing first-generation paclitaxel-eluting stents and second-generation "limus"-eluting stents in an all-comer population with small vessel disease are warranted.

\section{Corresponding author:}

Prof. Raban Jeger MD, PhD, Department of Cardiology and Clinical Trial Unit, University Hospital Basel, 4 Petersgraben St, 4031 Basel, Switzerland, phone: +41 612652525, e-mail: raban.jeger@usb.ch

Received: 21.08.2016, accepted: 1.10.2016. 


\section{Aim}

The aim of this pilot study was to assess the benefit of second-generation zotarolimus-eluting stents against first-generation paclitaxel-eluting stents regarding clinical events in the treatment of an all-comer population with small vessel disease.

\section{Material and methods}

The Late clinical events after paclitaxel- versus zotarolimus-eluting stents in patients with small vessel stenting (BASKET-SMALL Pilot) study was a single-centre randomised controlled trial that compared two different DES, i.e., the first-generation paclitaxel-eluting Taxus Liberté stent (Boston Scientific, Natick, MA) and the second-generation zotarolimus-eluting Endeavor Sprint stent (Medtronic, Minneapolis, MN) in the treatment of small vessel disease. The study was designed as a pilot study to estimate the required patient number for an intended larger pivotal trial and enrolled patients in parallel to another clinical stent trial for large vessel treatment [16]. Of note, the initial design of the study planned to compare the Taxus Liberte stent with another paclitaxel-eluting stent, i.e., the CoStar stent (Conor Medsystems, Menlo Park, CA). Unfortunately, this latter stent was withdrawn from the market because of unfavourable clinical results [17] and had to be replaced with another comparator stent after the inclusion of a small number of patients in the trial.

The inclusion criterion was small vessel $\mathrm{PCl}$ using at least one stent $<3.0 \mathrm{~mm}$ in diameter. Exclusion criteria were the following: in-stent restenosis, bypass graft disease, main stem disease to be treated, cardiogenic shock, planned surgery within the next 6 months, treatment with vitamin $\mathrm{K}$ antagonists, e.g., due to artificial heart valves or atrial fibrillation, no compliance expected, enrolled in another study, or no consent. The primary endpoint was major adverse cardiac events (MACE), i.e., a composite of cardiac death, non-fatal myocardial infarction, and target vessel revascularisation (TVR) after 2 years. Secondary endpoints were the single components of the primary endpoint and major non-coronary artery bypass graft surgery-associated bleeding defined as Bleeding Academic Research Consortium class $\geq 3$ [18]. Due to a lack of published data in the field, no formal sample size calculation was performed, but the study was designed as a pilot study with a fixed number of patients to be enrolled.

Percutaneous coronary intervention was performed according to the treating physician in charge. According to international guidelines applicable during the trial, concomitant medications consisted of aspirin $100 \mathrm{mg}$ and a statin indefinitely, and clopidogrel $75 \mathrm{mg}$ for 12 months after stent implantation with an adequate loading dose if indicated [19]. In addition, treatment included statins and other drugs if clinically indicated. Diabetes mellitus was defined either as the known diagnosis of the disease or ongoing treatment at baseline. The study was approved by the local Ethics Committee, and all patients gave written informed consent. An independent Clinical Endpoint Committee blinded to the randomisation groups adjudicated all endpoints.

\section{Statistical analysis}

The main statistical analysis was performed in the population randomised to the Taxus and Endeavor groups, while CoStar patients were analysed separately without formal statistical comparison due to the small number of patients in this group. Patient demographics and baseline data for each analysis set are reported overall and for each treatment arm, where relevant. Continuous variables are reported as mean and standard deviation. The median and the $1^{\text {st }}$ and $3^{\text {rd }}$ quartiles are reported separately. Categorical variables are reported as frequencies and percentages. Comparisons of demographics and baseline characteristics among the treatment arms were made using the Wilcoxon rank-sum test for continuous variables, or Fisher's exact test for categorical variables. Time-to-event endpoints are reported as Kaplan-Meier curves. Cox proportional hazards models, with stent type as the fixed variable, were used to compare hazards among the different stent types. Estimated hazard ratios $(\mathrm{HR})$ and their 95 confidence intervals $(\mathrm{Cl})$ are reported. In analyses where a treatment arm had no events, Firth's penalized likelihood bias reduction method was used to prevent non-convergence, as implemented in the $\mathrm{R}$ package cox-phf [20, 21]. The proportional hazards assumption was evaluated for each model; borderline cases were also evaluated by Renyi-type tests as a sensitivity analysis. In addition, the log-rank test was applied for each endpoint; $p$-values are reported. Unlike HR and corresponding Wald tests, log-rank tests are not hampered by missing events in one of the treatment arms. All analyses took 0.05 as the significance level. No adjustment was made for multiple testing. Based on the results of this pilot study, a sample size was calculated using a resampling approach. Each sample size $n_{i}=1, \ldots, 67=340$, ..., 2980 for superiority was evaluated by simulating for each trial $R=499$ times $n$ individual patients. Patients were simulated from binomial distributions with expected event rates as found in the BASKET-SMALL pilot data.

\section{Results}

A total of 200 patients were enrolled in the trial. Since the comparator stent had to be switched after the enrolment of 9 patients in the respective study arm, the study population comprised 191 patients, who were randomised to either the paclitaxel-eluting $(n=100)$ or the zotarolimus-eluting stents $(n=91)$.

Baseline characteristics between the two groups were well balanced (Table I). Patients were on average 
Table I. Baseline characteristics

\begin{tabular}{|c|c|c|c|c|}
\hline Parameter & $\begin{array}{c}\text { Overall } \\
(n=191)\end{array}$ & $\begin{array}{l}\text { Zotarolimus } \\
\quad(n=91)\end{array}$ & $\begin{array}{l}\text { Paclitaxel } \\
(n=100)\end{array}$ & $P$-value \\
\hline Age, mean \pm SD [years] & $64.6 \pm 11.3$ & $64.0 \pm 11.9$ & $65.2 \pm 10.7$ & 0.48 \\
\hline Male sex, $n(\%)$ & $151(79.1)$ & $72(79.1)$ & $79(79)$ & 1.00 \\
\hline Diabetes mellitus, $n$ (\%) & $41(21.5)$ & $21(23.1)$ & $20(20)$ & 0.72 \\
\hline Arterial hypertension, $n(\%)$ & $139(72.8)$ & $63(69.2)$ & $76(76)$ & 0.33 \\
\hline Hyperlipidaemia, $n$ (\%) & $112(58.6)$ & $52(57.1)$ & $60(60)$ & 0.77 \\
\hline Current smoker, $n$ (\%) & $63(33)$ & $32(35.2)$ & $31(31)$ & 0.64 \\
\hline Previous myocardial infarction, $n(\%)$ & $34(17.8)$ & $19(20.9)$ & $15(15)$ & 0.35 \\
\hline Previous $\mathrm{PCI}, n(\%)$ & $43(22.5)$ & $23(25.3)$ & $20(20)$ & 0.39 \\
\hline Previous CABG surgery, $n$ (\%) & $12(6.3)$ & $3(3.3)$ & $9(9)$ & 0.14 \\
\hline \multicolumn{5}{|l|}{ Clinical presentation, $n(\%)$ : } \\
\hline Stable angina & $85(44.5)$ & $43(47.3)$ & $42(42)$ & 0.47 \\
\hline Unstable angina & $69(36.1)$ & $30(33)$ & $39(39)$ & 0.45 \\
\hline ST-elevation myocardialinfarction & $37(19.4)$ & $18(19.8)$ & 19 (19) & 1.00 \\
\hline \multicolumn{5}{|l|}{ Treated coronary arteries, $n(\%)$ : } \\
\hline Leftanteriordescending & $103(53.9)$ & $56(61.5)$ & $47(47)$ & 0.06 \\
\hline Left circumflex & $104(54.5)$ & $51(56)$ & $53(53)$ & 0.77 \\
\hline Right coronary & $48(25.1)$ & $20(22)$ & $28(28)$ & 0.40 \\
\hline Multivessel disease, $n(\%)$ & $156(81.7)$ & $76(83.5)$ & $80(80)$ & 0.58 \\
\hline Bifurcation lesion, $n(\%)$ & $19(9.9)$ & $10(11)$ & $9(9)$ & 0.81 \\
\hline Chronic total occlusion, $n$ (\%) & $6(3.1)$ & $3(3.3)$ & $3(3)$ & 1.00 \\
\hline Additional stents $\geq 3.0 \mathrm{~mm}, n$ (\%) & $77(40.3)$ & $31(34.1)$ & $46(46)$ & 0.11 \\
\hline Use of glycoprotein IIb/IIla inhibitor, $n$ (\%) & $26(13.6)$ & $14(15.4)$ & $12(12)$ & 0.53 \\
\hline No. of treated segments per patient, mean \pm SD & $1.8 \pm 1.0$ & $1.8 \pm 1.1$ & $1.7 \pm 0.9$ & 0.67 \\
\hline No. of stents per patient, mean \pm SD & $2.2 \pm 1.3$ & $2.3 \pm 1.5$ & $2.1 \pm 1.2$ & 0.75 \\
\hline Total stent length per patient, mean \pm SD $[\mathrm{mm}]$ & $39.9 \pm 27.4$ & $42.2 \pm 30.9$ & $37.8 \pm 23.7$ & 0.59 \\
\hline Stent length per lesion, mean \pm SD $[\mathrm{mm}]$ & $22.9 \pm 10.3$ & $22.9 \pm 9.5$ & $22.9 \pm 10.9$ & 0.62 \\
\hline
\end{tabular}

64.6 years old, predominantly male (79.1\%), and presented with acute coronary syndrome in $55.5 \%$ of cases. Angiography showed multivessel disease in $81.7 \%$, bifurcation lesions in $9.9 \%$, and chronic total occlusions in 3.1\%. On average, patients were treated with 2.2 stents with a total length of $39.9 \mathrm{~mm}$. In $40.3 \%$ of cases, an additional stent $\geq 3 \mathrm{~mm}$ was placed.

After 2 years of follow-up, the MACE rate for the zotarolimus-eluting stent was twice the rate for paclitaxel-eluting stents, although this result was not statistically significant $(\mathrm{HR}=2.09,95 \% \mathrm{Cl}: 0.70-6.23, p=$ 0.19 , Figure 1 and Table II). There were similar results for cardiac death ( $\mathrm{HR}=2.22,95 \% \mathrm{Cl}: 0.20-24.46, p=0.52)$ and TVR ( $\mathrm{HR}=3.39,95 \% \mathrm{Cl}: 0.68-16.78, p=0.14)$, again without statistical significance. Rates for major bleeding $(\mathrm{HR}=0.22,95 \% \mathrm{Cl}: 0.00-2.69, p=0.26)$, non-fatal myocardial infarction $(\mathrm{HR}=0.76,95 \% \mathrm{Cl}: 0.13-4.56, p=$ $0.77)$, and all-cause death ( $\mathrm{HR}=0.84,95 \% \mathrm{Cl}: 0.19-3.76$, $p=0.82$ ) were similar between the groups.

In a secondary analysis within the group of diabetic patients ( $n=41,22 \%$ ), there was no significant interaction between diabetic status and randomisation regarding MACE at 24 months of follow-up $(\mathrm{HR}=0.86,95 \% \mathrm{Cl}$ : $0.08-11.76 ; p=0.90)$. In the diabetic subgroup, MACE 
rates at 24 months were similar as in the overall population (paclitaxel-eluting stent $5 \%$ vs. zotarolimus-eluting stent $10 \% ; p=0.58$; Figure 2).

Based on the primary endpoint of this pilot study, a sample size calculation for the performance of a superiority trial comparing the Taxus stent with the Endeavor stent was performed. With a significance level of $5 \%$, 1,019 patients would be necessary to ensure 968 evaluable patients at a power of $80 \%$, considering an overall dropout rate of $5 \%$.

Due to the small sample size, the CoStar population was not formally compared with the two randomised groups. Patients were on average 68.1 years old, $66.7 \%$ were male, and $77.8 \%$ had an acute coronary syndrome. Except for one major bleeding event, there were no clinical endpoints throughout the whole follow-up time, specifically no ischaemic event.

\section{Discussion}

This is the first randomised comparison of a first-generation paclitaxel-eluting stent vs. a second-generation zotarolimus-eluting stent in an all-comer population with small vessel disease. Event rates for MACE were below $10 \%$ after 2 years, which is surprising given the fact that all patients had small vessel disease and more than $50 \%$ of patients had acute coronary syndromes. Although not statistically significant, it showed a twofold higher event rate regarding MACE for the zotarolimus- vs. the paclitaxel-eluting stent. Based on these results, a sample size calculation was performed and showed that a trial of

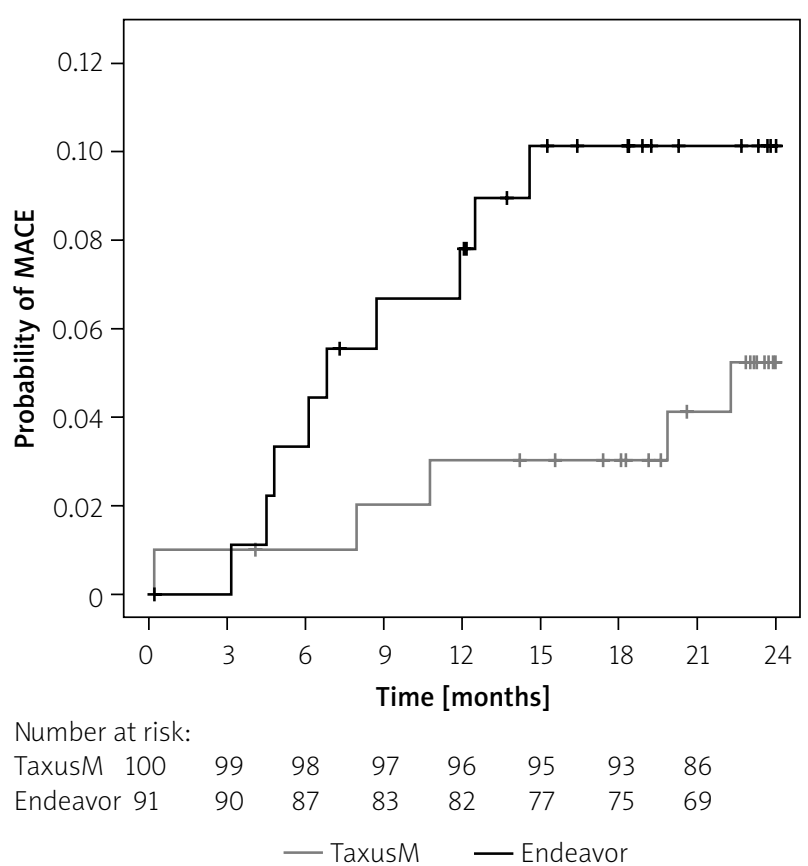

Figure 1. Kaplan-Meier estimates of MACE $(p=0.18)$

more than 1,000 randomised patients would be required to prove non-inferiority of the paclitaxel- regarding the zotarolimus-eluting stent.

The stents used in this trial were different in terms of stent body, strut size, polymer, and drug. The Taxus Liberté stent was a first-generation paclitaxel-eluting stent made from stainless steel with a strut size of 0.0038

Table II. Primary and secondary endpoints

\begin{tabular}{|c|c|c|c|c|c|c|}
\hline Outcome & Stent type & 12 months & 18 months & 24 months & $\mathrm{HR}(95 \% \mathrm{Cl})$ & $P$-value \\
\hline \multirow[t]{2}{*}{ MACE } & Taxus & $3(3.0 \%)$ & $3(3.0 \%)$ & $5(5.0 \%)$ & -ref.- & \\
\hline & Endeavor & $7(7.7 \%)$ & $9(9.9 \%)$ & $9(9.9 \%)$ & $2.09(0.70-6.23)$ & 0.19 \\
\hline \multirow[t]{2}{*}{ Cardiac death } & Taxus & $1(1.0 \%)$ & $1(1.0 \%)$ & $1(1.0 \%)$ & -ref.- & \\
\hline & Endeavor & $1(1.1 \%)$ & $2(2.2 \%)$ & $2(2.2 \%)$ & $2.22(0.20-24.46)$ & 0.52 \\
\hline \multirow[t]{2}{*}{ Non-fatal MI } & Taxus & $1(1.0 \%)$ & $1(1.0 \%)$ & $3(3.0 \%)$ & -ref.- & \\
\hline & Endeavor & $1(1.1 \%)$ & $2(2.2 \%)$ & $2(2.2 \%)$ & $0.76(0.13-4.56)$ & 0.77 \\
\hline \multirow[t]{2}{*}{ TVR } & Taxus & $2(2.0 \%)$ & $2(2.0 \%)$ & $2(2.0 \%)$ & -ref.- & \\
\hline & Endeavor & $6(6.6 \%)$ & $6(6.6 \%)$ & $6(6.6 \%)$ & $3.39(0.68-16.78)$ & 0.14 \\
\hline \multirow[t]{2}{*}{ Cardiac death/MI } & Taxus & $2(2.0 \%)$ & $2(2.0 \%)$ & $4(4.0 \%)$ & -ref.- & \\
\hline & Endeavor & $1(1.1 \%)$ & $3(3.3 \%)$ & $3(3.3 \%)$ & $0.85(0.19-3.80)$ & 0.83 \\
\hline \multirow[t]{2}{*}{ Major bleeding } & Taxus & $2(2.0 \%)$ & $2(2.0 \%)$ & $2(2.0 \%)$ & -ref.- & \\
\hline & Endeavor & $0(0.0 \%)$ & $0(0.0 \%)$ & $0(0.0 \%)$ & $0.22(0.00-2.69)$ & 0.26 \\
\hline \multirow[t]{2}{*}{ All-cause death } & Taxus & $2(2.0 \%)$ & $3(3.0 \%)$ & $4(4.0 \%)$ & -ref.- & \\
\hline & Endeavor & $2(2.2 \%)$ & $3(3.3 \%)$ & $3(3.3 \%)$ & $0.84(0.19-3.76)$ & 0.82 \\
\hline
\end{tabular}

Cl-confidence interval, HR - hazard ratio, MACE - major adverse cardiac events, MI-myocardial infarction, TVR-target vessel revascularization. Hazard ratios and $p$-values calculated from Cox-PH models; $p$-value from log-rank test provided as well. 


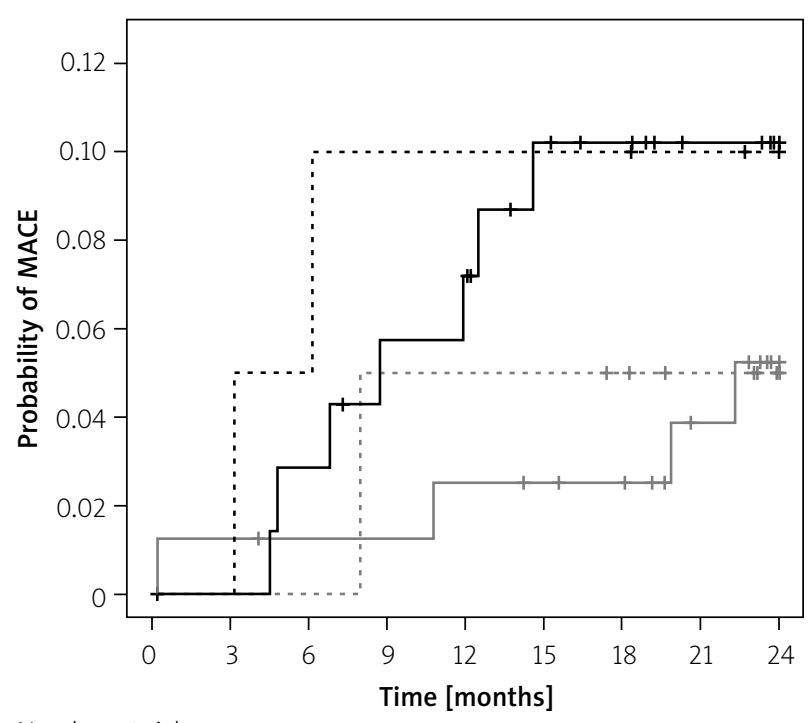

Number at risk:

TaxusM: DO

\begin{tabular}{|c|c|c|c|c|c|c|c|}
\hline 80 & 79 & 78 & 78 & 77 & 76 & 75 & 70 \\
\hline \multicolumn{8}{|l|}{ TaxusM: D1 } \\
\hline 20 & 20 & 20 & 19 & 19 & 19 & 18 & 16 \\
\hline \multicolumn{8}{|l|}{ Endeavor: DO } \\
\hline 70 & 70 & 68 & 65 & 64 & 59 & 57 & 52 \\
\hline \multicolumn{8}{|l|}{ Endeavor: D1 } \\
\hline 21 & 20 & 19 & 18 & 18 & 18 & 18 & 17 \\
\hline & & Tax & 1: DO & & & & \\
\hline & - & ndea & r: DO & & $\ldots E r$ & avo & \\
\hline
\end{tabular}

Figure 2. Kaplan-Meier estimates of MACE, stratified by the presence (D1, $p=0.58)$ or absence of diabetes mellitus (D0, $p=0.23$ )

inches $(0.097 \mathrm{~mm})$ coated with the durable, non-erodible polymer polyolefin. In contrast, the Endeavor Sprint stent was a second-generation zotarolimus-eluting stent made from a cobalt-chromium alloy with a strut size of 0.0036 inches $(0.091 \mathrm{~mm})$ coated with the durable polymer phosphorylcholine designed for better biocompatibility by mimicking a natural cell membrane. Regarding small vessel disease, the two stents have been compared in subgroups of randomised controlled trials for efficacy and safety before. The Randomized, Controlled Trial of the Medtronic Endeavor Drug [ABT-578] Eluting Coronary Stent System Versus the Taxus Paclitaxel-Eluting Coronary Stent System in De Novo Native Coronary Artery Lesions (ENDEAVOR IV) [22] randomised 1,548 patients to receive either the paclitaxel-eluting Taxus Express stent or the zotarolimus-eluting Endeavor Sprint stent and showed similar rates of target vessel failure, i.e., the composite of cardiac death, myocardial infarction, and symptom-driven target lesion revascularisation after 1 (9.5 vs. $7.7 \%, p=0.188)$ and 2 years (13.1 vs. $11.1 \%$, $p=0.220)$. In $71 \%$ of patients, a stent $<3.0 \mathrm{~mm}$ was implanted, with similar results as in the overall cohort ( $p$ for interaction 0.865). In addition, the Comparison of the efficacy and Safety of Zotarolimus-Eluting Stent with
Sirolimus-Eluting and PacliTaxel-Eluting Stent for Coronary Lesions (ZEST) Randomized Trial [23] randomised 2,645 patients to either the paclitaxel-eluting Taxus Liberté stent, the sirolimus-eluting Cypher Select stent (Cordis Johnson \& Johnson, Miami Lakes FL), or the zotarolimus-eluting Endeavor Driver stent and showed the lowest rates for sirolimus-eluting stents when compared with zotarolimus-eluting and paclitaxel-eluting stents after 12 months (8.3 vs. 10.2 vs. $14.1 \%, p<0.001$ ). In $38 \%$ of patients, a stent $<3.0 \mathrm{~mm}$ was implanted, with a relative risk of $1.12(0.73-1.71)$ favouring the sirolimusvs. the zotarolimus-eluting stent and $0.65(0.45-0.93) \mathrm{fa}-$ vouring the zotarolimus- vs. the paclitaxel-eluting stent. Therefore, the trials were somewhat discrepant, but zotarolimus-eluting stents were at least similar to paclitaxel-eluting stents in these post-hoc comparisons for small vessel disease.

In patients with diabetes mellitus, small vessel disease is usually more prevalent than in the normal population due to the more aggressive form of atherosclerosis. Based on some subgroup analyses of trials in patients with diabetes mellitus that showed a potential benefit of paclitaxel- compared with "limus"-eluting stents, a theory of potentially better efficacy of paclitaxel-eluting stents in small vessel disease emerged [9-11]. However, the recently published Taxus Element versus Xience Prime in a Diabetic Population (TUXEDO)-India Trial [12] refuted this theory and showed a higher rate of target-vessel failure in paclitaxel-eluting stents compared with the comparator everolimus-eluting stent (5.6 vs. $2.9 \%, \mathrm{HR}=$ $1.89,95 \% \mathrm{Cl}: 1.20-2.99, p=0.005)$, at least in a diabetic Asian population.

Paclitaxel- and "limus"-eluting stents have been compared in many trials before, with better results for "limus" regarding clinical outcomes [24]. In contrast to the above-mentioned studies, the present dedicated small vessel trial showed a relative benefit of paclitaxel- vs. zotarolimus-eluting stents in an all-comer population with only $22 \%$ diabetic patients. However, due to the small sample size, this result was not statistically significant. Given the discrepancy between the current study and previous findings from retrospective subgroup analyses of larger trials and of a dedicated trial in diabetic patients, it may be hypothesised that paclitaxel-eluting stents have a similar efficacy as or even a relative benefit over "limus"-eluting stents in low-risk small vessel disease without diabetes mellitus but an inferior efficacy in high-risk small vessel disease with diabetes mellitus. It is possible that the effect of the antiproliferative drug coating with inhibition of the proliferation of endothelial and smooth muscle cells may be less important in small than large coronary vessels, specifically if a high-risk situation like diabetes mellitus is not present [25].

A sample size calculation based on the results of our trial demonstrated that a population of more than 1,000 patients would be required for a randomised con- 
trolled trial to prove non-inferiority of paclitaxel- versus zotarolimus-eluting stents in low-risk small vessel disease. However, a pivotal trial of this size would be difficult to perform and seems to be futile at the present time. Therefore, the plan to perform a larger trial comparing two different stent types in small vessel disease was abandoned; instead, a multicentre randomised trial comparing DES with drug-coated balloons was designed and is currently recruiting patients (ClinicalTrials. gov Identifier: NCT01574534). Drug-coated balloons exhibit special properties such as drug release limited to the time of the highest activity of the neointimal overgrowth after barotrauma and uniform, strut-independent drug delivery [26]. They have been tested against paclitaxel-eluting stents in small native coronary vessels and showed discrepant findings [27, 28], but represent a promising treatment modality for this indication $[15,29]$.

Given the nature of the present single-centre pilot trial, this analysis has several limitations. First, patients were enrolled at a single centre, and the number of patients was not sufficient to provide significant results. However, based on the good quality of the data and the design of the study as a pilot trial, these limitations may be of minor importance. Second, both stents used are not available any more in many parts of the world. However, there are still successor products for both stents with similar characteristics on the market; therefore, the results of this trial may still be valid. Third, one initial comparator stent was omitted and replaced with another stent during the study. However, the initial comparator stent was taken off the market in May 2007, and a valid replacement product was sought and found at short notice. Finally, the higher event rate of zotarolimus-eluting compared with paclitaxel-eluting stents was not statistically significant and, therefore, may be a result of chance.

\section{Conclusions}

In lesions of small coronary vessels, first-generation paclitaxel-eluting and second-generation zotarolimuseluting stents have similar outcomes after 1 year, with numerically higher rates for the second-generation "limus"-eluting stent. A sample size calculation on the basis of the present results yields a prohibitive number of patients to be enrolled in an adequately powered clinical trial. Therefore, novel alternatives to DES may be useful in lieu of DES for the treatment of lesions in small coronary vessels, e.g., drug-coated balloons. A relevant randomised controlled trial in small vessel disease is currently under way.

\section{Acknowledgments}

Funding: Basel Cardiovascular Research Foundation, Basel, Switzerland.

\section{Conflict of interest}

The authors declare no conflict of interest.

\section{References}

1. Brunner-La Rocca H, Kaiser C, Pfisterer M. Targeted stent use in clinical practice based on evidence from the Basel Stent Cost Effectiveness Trial (BASKET). Eur Heart J 2007; 28: 719-25.

2. Ardissino D, Cavallini C, Bramucci E, et al. Sirolimus-eluting vs uncoated stents for prevention of restenosis in small coronary arteries: a randomized trial. JAMA 2004; 292: 2727-34.

3. Stone G, Ellis S, Cannon L, et al. Comparison of a polymer-based paclitaxel-eluting stent with a bare metal stent in patients with complex coronary artery disease: a randomized controlled trial. JAMA 2005; 294: 1215-23.

4. Siontis GC, Piccolo R, Praz F, et al. Percutaneous coronary interventions for the treatment of stenoses in small coronary arteries: a network meta-analysis. JACC Cardiovasc Interv 2016; 9 : 1324-34.

5. Mehilli J, Dibra A, Kastrati A, et al. Randomized trial of paclitaxeland sirolimus-eluting stents in small coronary vessels. Eur Heart J 2006; 27: 260-6.

6. Morice M, Colombo A, Meier B, et al. Sirolimus-vs paclitaxel-eluting stents in de novo coronary artery lesions: the REALITY trial: a randomized controlled trial. JAMA 2006; 295: 895-904.

7. Gershlick A, Kandzari DE, Leon MB, et al. Zotarolimus-eluting stents in patients with native coronary artery disease: clinical and angiographic outcomes in 1,317 patients. Am J Cardiol 2007; 100: 45M-55M.

8. Tanimoto S, Daemen J, Tsuchida K, et al. Two-year clinical outcome after coronary stenting of small vessels using 2.25$\mathrm{mm}$ sirolimus- and paclitaxel-eluting stents: insight into the RESEARCH and T-SEARCH registries. Catheter Cardiovasc Interv 2007; 69: 94-103.

9. Daemen J, Garcia-Garcia HM, Kukreja N, et al. The long-term value of sirolimus- and paclitaxel-eluting stents over bare metal stents in patients with diabetes mellitus. Eur Heart J 2007; 28: 26-32.

10. Ong AT, Aoki J, van Mieghem CA, et al. Comparison of short- (one month) and long- (twelve months) term outcomes of sirolimusversus paclitaxel-eluting stents in 293 consecutive patients with diabetes mellitus (from the RESEARCH and T-SEARCH registries). Am J Cardiol 2005; 96: 358-62.

11. Stankovic G, Cosgrave J, Chieffo A, et al. Impact of sirolimus-eluting and paclitaxel-eluting stents on outcome in patients with diabetes mellitus and stenting in more than one coronary artery. Am J Cardiol 2006; 98: 362-6.

12. Kaul U, Bangalore S, Seth A, et al. Paclitaxel-eluting versus everolimus-eluting coronary stents in diabetes. N Engl J Med 2015; 373: 1709-19.

13. Tanimoto S, Serruys P, Thuesen L, et al. Comparison of in vivo acute stent recoil between the bioabsorbable everolimus-eluting coronary stent and the everolimus-eluting cobalt chromium coronary stent: insights from the ABSORB and SPIRIT trials. Catheter Cardiovasc Interv 2007; 70: 515-23.

14. Cannon LA, Kereiakes DJ, Mann T, et al. A prospective evaluation of the safety and efficacy of TAXUS Element paclitaxel-eluting coronary stent implantation for the treatment of de novo coronary artery lesions in small vessels: the PERSEUS Small Vessel trial. Eurolntervention 2011; 6: 920-7, 1-2. 
15. Alfonso F, García-Guimaraes M. Optimal coronary interventions in small vessels: is size all that matters? JACC Cardiovasc Interv 2016; 9: 1335-7.

16. Kaiser C, Galatius S, Erne P, et al.; Group tBPS. Drug-eluting versus bare-metal stents in large coronary arteries. N Engl J Med 2010; 363: 2310-2319.

17. COSTAR II Presentation EuroPCR 2007 (http://www.pcronline. com/Lectures/2007/COSTAR-II-primary-outcome-results).

18. Mehran R, Rao SV, Bhatt DL, et al. Standardized bleeding definitions for cardiovascular clinical trials: a consensus report from the Bleeding Academic Research Consortium. Circulation 2011; 123: 2736-47.

19. Silber S, Albertsson P, Avilés F, et al.; Cardiology TFfPClotESo. Guidelines for percutaneous coronary interventions. The Task Force for Percutaneous Coronary Interventions of the European Society of Cardiology. Eur Heart J 2005; 26: 804-47.

20. Firth D. Bias reduction of maximum likelihood estimates. Biometrika 1993; 80: 27-38.

21. Heinze G, Schemper M. A solution to the problem of monotone likelihood in Cox regression. Biometrics 2001; 57: 114-9.

22. Leon M, Kandzari D, Eisenstein E, et al. Late safety, efficacy, and cost-effectiveness of a zotarolimus-eluting stent compared with a paclitaxel-eluting stent in patients with de novo coronary lesions: 2-year follow-up from the ENDEAVOR IV trial (Randomized, Controlled Trial of the Medtronic Endeavor Drug [ABT-578] Eluting Coronary Stent System Versus the Taxus Paclitaxel-Eluting Coronary Stent System in De Novo Native Coronary Artery Lesions). JACC Cardiovasc Interv 2009; 2: 1208-18.

23. Park DW, Kim YH, Yun SC, et al. Comparison of zotarolimus-eluting stents with sirolimus- and paclitaxel-eluting stents for coronary revascularization: the ZEST (comparison of the efficacy and safety of zotarolimus-eluting stent with sirolimus-eluting and paclitaxel-eluting stent for coronary lesions) randomized trial. J Am Coll Cardiol 2010; 56: 1187-95.

24. Palmerini T, Benedetto U, Biondi-Zoccai G, et al. Long-term safety of drug-eluting and bare-metal stents: evidence from a comprehensive network meta-analysis. J Am Coll Cardiol 2015; 65: 2496-507.

25. Wessely R, Schomig A, Kastrati A. Sirolimus and paclitaxel on polymer-based drug-eluting stents: similar but different. J Am Coll Cardiol 2006; 47: 708-14.

26. Byrne RA, Joner M, Alfonso F, Kastrati A. Drug-coated balloon therapy in coronary and peripheral artery disease. Nat Rev Cardiol 2014; 11: 13-23.

27. Cortese B, Micheli A, Picchi A, et al. Paclitaxel-coated balloon versus drug-eluting stent during $\mathrm{PCl}$ of small coronary vessels, a prospective randomised clinical trial. The PICCOLETO study. Heart 2010; 96: 1291-6.

28. Latib A, Colombo A, Castriota F, et al. A randomized multicenter study comparing a paclitaxel drug-eluting balloon with a paclitaxel-eluting stent in small coronary vessels: the BELLO (BalIoon Elution and Late Loss Optimization) study. J Am Coll Cardiol 2012; 60: 2473-80.

29. Byrne RA, Joner M. Drug-coated balloon angioplasty for de novo stenosis: the balloon is back...reloaded! JACC Cardiovasc Interv 2015; 8: 2010-2. 